\title{
'I have never lost my love for treating anxious children'
}

\author{
Neil Oastler has been honoured with Life Membership of the British \\ Dental Association (BDA) this year. Neil reflects on his career path through \\ dentistry, the impact of the pandemic in his retirement year, and why he \\ was nominated for the BDA award.
}

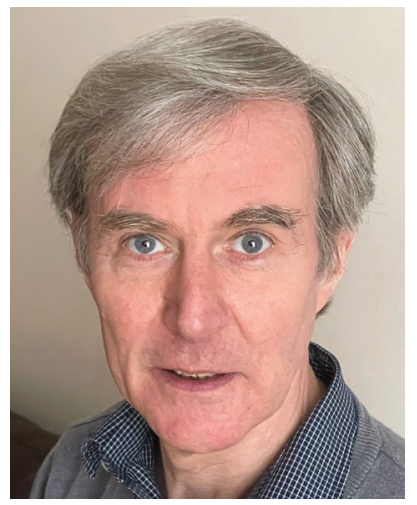

I was born an only child in 1960 and raised in Horley, a small town in Surrey, close to Gatwick Airport. I attended one of the local primary schools and on passing my 11 plus went to Reigate Grammar School.

There is no history of dentistry in my family. I was attracted to dentistry first by my local dentist in Horley, Robert Cramp, a Guy's graduate, like his father. Recognising my fascination with machinery, Robert would let me play with the 3 in 1, spittoon and most fascinating of all, the pulleydriven handpiece. I loved going to the dentist, insisting on 'going in' without my mum because I was a 'big boy' and running out in tears, followed by a flustered Robert, who quickly had to explain the reason for my distress was because I didn't need a filling - I was adamant that I wanted one!

So it was inevitable, perhaps, that dentistry was always to be my chosen profession. There was never any need for career advice at school and all subject choices and extra-curricular activities were geared towards applying to Guy's.

I was accepted there and started studying in September 1978, graduating in 1983, but not without flunking finals first time around, which is a very long story of misfortune, but was - with the benefit of hindsight - the best thing that ever happened to me.

During the enforced extra six months of undergraduate training, I 'worked' as an assistant house surgeon for three months in the restorative department under the mentorship of Professor Jack Rowe and in the oral surgery department where Paul Shepard taught me how to take out teeth and Meg Skelly how to sedate anxious

patients. Graduation was followed by a house job at Guy's, exposure to working in theatres and then, fortuitously, what was the most sought-after of junior training jobs, at Queen Mary's Roehampton, established and made famous by Norman Rowe. Had I graduated six months earlier, the Roehampton job wouldn't have been advertised. I would not have worked alongside some great surgeons who saw my potential and polished a very rough diamond over the subsequent 18 months; and of course, I wouldn't have met my wife of 35 years and counting, who was working in the A\&E department there and was called upon to treat an injury I sustained in theatre late one evening.

\section{'I am humbled to realise that colleagues have felt that I have made a difference to them'}

In 1985, I needed to make the difficult choice between continuing in oral and maxillofacial surgery and taking up a place to study medicine at Westminster, or general practice. As we were planning to get married, I chose the latter as being the more financially stable option and less of a strain on a new relationship. Thus, we moved to Gloucester, for me to work at Saunders Dental Practice, then a totally NHS, city centre practice, where I replaced Nick's father Brian who had died suddenly.

It is very daunting as a young graduate replacing a practice owner of 40 years standing; you quickly have to learn to have confidence in your own ability when you hear 'Brian wouldn't have done it like that' eight times a day. The practice was forward thinking, offering paediatric extractions under GA and treatment under sedation. It went through a gradual transformation to a mixed private/NHS practice precipitated by the fall-out from contract in 1990.

Whilst in Gloucestershire, I was able to continue my oral surgery working as a clinical assistant or doing locum registrar shifts in the local max-fac department, where two of the consultants were former registrars from my days at Queen Mary's.

By 1994, I had become disillusioned with general practice, and was yearning towards working full time in the management of the anxious child and special care patient, which frankly is hard to make profitable in general practice. I turned down the offer of a partnership and headed for Oxfordshire and a job as a dental officer with the community dental service. This was a dramatic drop in salary but with the compensation of job satisfaction and a better work-life balance, especially with twins not yet three-years-old on the scene. And that is where I remained for the next 26 years, subsequently as a senior dental officer and the appointment as a specialist lead clinician in 2008.

The creation of Specialist Lists allowed me to be 'grandparented' onto the Surgical Dentist List in 2000 supported by attainment of FDS in 1997 and being in the first cohort of dentists ever awarded 
14 the DPDS (Bristol) in 1994, a result of my constant working in and around oral surgery units since graduation and the testimonies of the aforementioned consultants who had worked with me since my early days as a house officer.

A forward-thinking consultant in dental public health, David Thomas (a subsequent CDO for Wales) acquired funding for a pilot to deliver oral surgery in primary care, initially just by me, but subsequently by many other like-minded colleagues, which started in 2000 and was still running until the trust lost the tender in 2020. in local practitioners to be involved with LDCs, I have organised study days for the whole practice team, to run alongside the AGMs. The most successful study day was to celebrate 60 years of our LDC in 2012. It took place at an Oxford College and was attended by 120 people, followed by a sumptuous meal attended by former officers, with John Milne as the guest of honour.

I feel very fortunate to have been a dentist and I have tried to always give something back to a profession and the NHS that has given me so much. Aside

\section{'It is very daunting as a young graduate replacing a practice owner of 40 years standing; you quickly have to learn to have confidence in your own ability'}

Despite the emphasis on oral surgery, I have never lost my love for treating anxious children and special care patients, particularly those with a learning disability. This affinity was established back in my teens where I volunteered as a helper at a weekly youth club for learning disabilities and during school holidays in the occupational therapy department at the Royal Earlswood Hospital. One has to remember this predates care in the community placements, and large institutions such as these were the norm.

During my time in the Oxfordshire CDS, I was tasked with taking on and running the Out of Hours dental service established when out of hours dentistry was removed from the NHS contract in 2006. Again, something I did up until my retirement, using the model that had previously been established by David Thomas for unregistered NHS patients in Oxfordshire, since 1991, and that I had worked for since arriving in Oxfordshire.

In 2004, the local LDC redrafted its constitution and asked for elected members not just from GDS but the CDS also. I was the only person motivated to put myself forward. I attended my first meeting and somehow managed to be arm twisted into becoming the Minutes and Meeting secretary, which I'm still doing 17 years later, as I haven't managed to twist anybody's arm sufficiently to take over from me. To try and engender interest from my LDC work, I was a council member for the British Association of Oral Surgeons (BAOS) from 2012-2018 and the Association of Dental Anaesthetists (ADA), from 2010-2021. I am still the Chair of the Managed Clinical Network for Oral Surgery for Thames Valley, a position I have held since 2015. I have also been a staff governor of my employing NHS Foundation trust for nearly six years.

I was always due to retire when I was 60 which was at the end of June 2020. My last three months of working were therefore blighted by the first pandemic lockdown. It was apparent that the overnight closure of dental practices would place an intolerable burden on out of hours services and hospital A\&E departments. Supported by my clinical director and a dynamic team of senior colleagues, we decided to transform our out of hours service from an evening and weekend service to an allday, seven days a week emergency dental service across multiple sites. We embraced remote and video triaging and liaised with regional pharmacies to work around the problem of digital prescribing. Because our out of hours service had always worked alongside medical out of hours and with 111 , the patient pathways were easily established. The senior directors of our hosting foundation trust (Oxford Health) were fantastic in supporting our efforts, especially around PPE acquisition. In effect we had created - virtually overnight - the first UDC, certainly in the South East if not the country. I hardly left my kitchen table from the end of March until the end of June. My leaving party was held socially distanced in the car park at work!

I continue to work for my old employer, undertaking a few sessions of theatrebased work, and for the out of hours service. I admire the fortitude of my former colleagues struggling to cope with the rigour of having to work day in, day out under enhanced PPE, prioritising the care of patients on ever lengthening waiting lists. I am ashamed that I feel glad that I don't have to work full time anymore as they do. It is only through unstinting dedication and going above and beyond that they manage to provide such an effective service at such a difficult time.

If I am asked why I think I was nominated for a BDA award, I would have to say that I am humbled to realise that colleagues have felt that I have made a difference to them through what I have done locally through the LDC, what I have done for patients throughout my CDS service, leading the Out of Hours dental service before and during a pandemic, and making a contribution to the furtherment of specialties by serving on national committees. It shows that an ordinary jobbing dentist like myself can be recognised for an award, if someone takes the trouble to nominate them, as in my case.

Post-pandemic, whenever that may be, I am looking forward, as we all are, to going out with friends and family, hugging, and holidaying whenever and wherever I want.

As for dentistry, I hope that a new dental contract is forthcoming that benefits patients and professionals alike. Sadly, every contract that I have worked through has been a retrograde step benefitting no one. My wish for medical and dental services post-Brexit is that our political masters finally see the folly of procurement and tendering of services. I have only ever seen it produce pain and suffering and loss of livelihood and I have never seen it deliver the improvement in service it has been meant to deliver.

To find out more about the BDA's Honours and Awards, and to nominate someone, visit www.bda. org/honoursawards. The deadline for nominations is 28 May 2021. 